\title{
Physicochemical and biological properties of a novel injectable polyurethane system for root canal filling
}

This article was published in the following Dove Press journal:

International Journal of Nanomedicine

17 January 2015

Number of times this article has been viewed

\author{
Jian Wang' \\ Yi Zuo' \\ Minghui Zhao' \\ Jiaxing Jiang' \\ Yi Man² \\ Jun $\mathrm{Wu}^{3}$ \\ Yunjiu $\mathrm{Hu}^{3}$ \\ Changlei $\mathrm{Liu}^{4}$ \\ Yubao $\mathrm{Li}^{1}$ \\ Jidong $\mathrm{Li}^{1}$
}

'Research Center for Nano-

Biomaterials, Analytical and Testing

Center, Sichuan University, Chengdu,

Sichuan, People's Republic of

China; ${ }^{2}$ College of Stomatology,

Sichuan University, Chengdu,

Sichuan, People's Republic of China;

${ }^{3}$ Department of Orthopedics,

Chongqing Medical University,

Chongqing, People's Republic

of China; ${ }^{4}$ College of Chemistry,

Sichuan University, Chengdu, Sichuan,

People's Republic of China
Correspondence: Jidong Li

Research Center for Nano-Biomaterials,

Analytical and Testing Center, Sichuan

University, Chengdu, Sichuan, People's

Republic of China 610064

Tel +86 28 854I 8178

$\mathrm{Fax}+862885418178$

Email nic1979@scu.edu.cn
Abstract: A root canal sealer with antibacterial activity can be efficacious in preventing reinfection that results from residual microorganisms and/or the leakage of microorganisms. In the present study, a series of injectable, self-curing polyurethane (PU)-based antibacterial sealers with different concentrations of silver phosphate $\left(\mathrm{Ag}_{3} \mathrm{PO}_{4}\right)$ were fabricated. Subsequently, their physicochemical properties, antibacterial abilities, and preliminary cytocompatibilities were evaluated. The results indicated that the fabricated PU-based sealers can achieve a high conversion rate in a short amount of time. More than $95 \%$ of the isocyanate group of PU sealers with $3 \mathrm{wt} \%$ (PU3) and $5 \mathrm{wt} \%$ (PU5) concentrations of $\mathrm{Ag}_{3} \mathrm{PO}_{4}$ were included in the curing reaction after 7 hours. With the exception of those for film thickness for PU5, the results of setting time, film thickness, and solubility were able to meet the requirements of the International Organization for Standardization. The antibacterial tests showed that PU3 and PU5 exhibit stronger antimicrobial effects than that achieved with $1 \mathrm{wt} \% \mathrm{Ag}_{3} \mathrm{PO}_{4}$ (PU1) and AH Plus (positive control) against Streptococcus mutans. The cytocompatibility evaluation revealed that the PU1 and PU3 sealers possess good cytocompatibility and low cytotoxicity. These results demonstrate that the PU3 sealer offers good physicochemical and antimicrobial properties along with cytocompatibility, which may hold great application potential in the field of root canal fillings.

Keywords: root canal sealer, polyurethane, silver phosphate, antibacterial properties, direct contact test

\section{Introduction}

The ultimate goal of root canal therapy is to eliminate microorganisms thoroughly while avoiding reinfection via good three-dimensional root canal obturation. ${ }^{1}$ The application of endodontic sealers after biomechanical cleaning, which is a common procedure, has been used to prevent and cure periapical periodontitis. ${ }^{2}$ However, it has been reported that even after rigid chemomechanical preparation, microorganisms in the lateral canals, dentinal tubules, and apical ramifications still cannot be cleaned thoroughly., If the access cavity is sealed incompletely, passages for bacteria, fluid, and chemical substance penetration are apt to be created when the root canals are not well obturated. 5,6 This situation commonly occurs because the currently available sealers, such as the most widely used root filling material (thermoplastisized Guttapercha), exhibit volume shrinkage after cooling. ${ }^{7}$ The residual organisms and bacteria from the oral cavity could rapidly reenter and proliferate in the empty canals and can subsequently induce or sustain periapical periodontitis. ${ }^{8,9}$

To overcome these drawbacks, it is best that root canal materials with antibacterial properties be used, ${ }^{10}$ as they may be efficacious for preventing the leakage of microorganisms 
and their byproducts around the margins of the material; such leakage leads to overall failure of the filling. However, inherent antimicrobial properties of the currently available sealers, such as epoxy resin sealers and zinc-oxide-eugenol-based sealers, ${ }^{2}$ are transient and rarely extend beyond 7 days, which is insufficient for protection against persistent bacterial infections. ${ }^{11}$ Moreover, the oral cavity is a complex environment that is composed of various bacteria, whereas the currently available antibacterial sealers exhibit sensitivity to only some kinds of these bacteria. ${ }^{1}$ Silver ions and silver compounds are known to display strong antimicrobial activity and offer a broad antibacterial spectrum, ${ }^{12,13}$ and these compounds have been applied in bactericidal products, including catheters, wound dressings, textiles, composite coatings, bone cements, and dental materials. ${ }^{14,15}$ A previous study has proved that the $\mathrm{Ag}^{+}$ provided inhibitive effects on oral bacteria, such as Porphyromonas gingivalis, Prevotella intermedia, and Fusobacterium nucleatum. ${ }^{16,17}$ Therefore, the incorporation of silver ions or silver compounds in sealers may be advantageous.

As a segmented polymer, polyurethane (PU) has drawn much attention as a candidate for biomaterials ${ }^{18}$ that are useful in contact lenses, thermally-sensitive materials, and dental materials ${ }^{19,20}$ because of its good mechanical properties, its blood compatibility, and its versatile molecular structure. When designing injectable polymeric materials, a PU sealer can provide multiple advantages, ${ }^{21,22}$ such as controllable fluidity and fast curing. More importantly, the volume of the PU materials slightly increases after polymerization and thus could conform to the requirements of hermetic obturation. In our previous study, ${ }^{22}$ the novel PU-based sealer exhibited slight volumetric dilatancy, and it offered good physicochemical properties and biocompatibility. Its low cytotoxicity can be attributed to the high conversion rate of monomers in the PU polymerization process. Therefore, the incorporation of antimicrobial agents into a tailored PU sealer could retain the merits of the PU-based endodontic sealers and simultaneously endow the sealer with antibacterial properties; the final product would be useful for preventing the growth of the remaining microorganisms.

The purpose of the current study is to develop a novel injectable self-curing PU-based antibacterial root canal sealer by incorporating silver phosphate $\left(\mathrm{Ag}_{3} \mathrm{PO}_{4}\right)$ particles, which can evenly distribute within the material; the release of $\mathrm{Ag}^{+}$ could provide satisfactory antibacterial effects. The selfcuring polymerization process, physicochemical properties, antibacterial activities, and preliminary cytocompatibilities of the novel antibacterial PU-based sealers were investigated in terms of their potential clinical application.

\section{Materials and methods Materials}

Polytetramethylene ether glycol (PTMEG 2000), triethanolamine, polyethylene glycol (PEG 600), and isophorone di-isocyanate (IPDI) were obtained from Aladdin Reagents (Shanghai, People's Republic of China), and $\mathrm{Ag}_{3} \mathrm{PO}_{4}$ was bought from J\&K Scientific Ltd. (Beijing, People's Republic of China). For this study, 1,4-butanediol (BDO) was dehydrated under decompression in a vacuum of 1,330 $\mathrm{Pa}$ at $120^{\circ} \mathrm{C}$. All reagents were of analytical reagent grade.

\section{Preparation of PU-based root canal sealer}

PU-segmented copolymers were prepared in a two-step process during which hydroxyl $(\mathrm{OH})$ groups and isocyanate (NCO) groups were created. First, HO-terminated soft segment (PTMEG) was degassed and dried in a round flask under high vacuum $(20 \mathrm{~Pa})$ at $105^{\circ} \mathrm{C}$ for 1.5 hours. After cooling to $70^{\circ} \mathrm{C}$, IPDI was charged into the flask in a molar ratio of 2:1 (NCO:OH), and the temperature of the mixture in the flask was kept at $70^{\circ} \mathrm{C}$ for 5 hours. Then, BDO (its mass is $1 / 45$ of PTMEG) as a chain extender was charged into the flask, and the reaction system was kept at $70^{\circ} \mathrm{C}$ for 2 hours under stirring, resulting in the NCO-terminated $\mathrm{PU}$ prepolymer (Pre-PU), which was named Component A. This reaction process was performed under an $\mathrm{N}_{2}$ atmosphere, and if $\mathrm{Ag}_{3} \mathrm{PO}_{4}$ (particle diameter of $\sim 200 \mathrm{~nm}$ ) was used during synthesis, it was added with the IPDI.

Component B was prepared by mixing dibutyltin dilaurate, triethanolamine, and PEG with a mass ratio of 1:15:6 at room temperature (about $25^{\circ} \mathrm{C}$ ).

The PU-based root canal sealer was prepared by mixing Component A and Component B at a mass ratio of 50:1 at room temperature. The mixture, which was then put into a syringe, was injectable during the initial period and then gradually solidified at body temperature. The weight percentage of $\mathrm{Ag}_{3} \mathrm{PO}_{4}$ in the final products was $0 \mathrm{wt} \%$ (PU0), $1 \mathrm{wt} \%$ (PU1), $3 \mathrm{wt} \%$ (PU3), and $5 \mathrm{wt} \%$ (PU5). The PU1, PU3, and PU5 sealers served as the experimental group. The PU0 sealer and the commercial sealer, AH Plus ${ }^{\circledR}$ (Dentsply, York, PA, USA), were used as the negative control group and the positive control group, respectively.

\section{Fourier transform infrared spectroscopy analysis}

Fourier transform infrared (FTIR) spectra were recorded on a FTIR spectrometer (Nicolet ${ }^{\mathrm{TM}}$ 6700; Thermo Fisher Scientific, Waltham, MA, USA) to investigate the polymerization process and the degree of conversion of the reagent monomer. 
Each sample was scanned 32 times with a resolution setting of $4 \mathrm{~cm}^{-1}$ and averaged to produce each spectrum. The degree of conversion was calculated by comparing the peak area of the NCO group at different curing times.

The conversion degree, $p$, can be expressed as the following equation. ${ }^{23}$

$$
p(t)=\int_{0}^{t} d p
$$

where $t$ represents reaction time during the process. Assuming that no side reactions occur, the degree of conversion $(p)$ can be used as the degree of curing:

$$
\text { Degree of conversion }(p)=1-\frac{A_{t}-A_{\infty}}{A_{0}-A_{\infty}} \text {. }
$$

Here, $A_{0}$ is the integrated absorption area at the initial time, $A_{t}$ is the integrated absorption area at time $t$ during the process, and $A_{\infty}$ is the final integrated absorption area. Since all of the NCO groups will be consumed in the polymerization process, $A_{\infty}$ is zero.

\section{Evaluation of physical properties}

The physical properties, including setting time, film thickness, solubility, and dimensional change of the PU-based root canal sealers, were evaluated according to the International Organization for Standardization (ISO 6876:2001[E]).

\section{Antimicrobial properties assessment}

The Streptococcus mutans strain (S. mutans ATCC 25175) that was grown aerobically in brain-heart infusion (BHI) broth (Oxoid Ltd, Basingstoke, UK) at $37^{\circ} \mathrm{C}$ for 48 hours and the inoculum density of $10^{6}$ colony-forming units (CFUs)/mL were used for the antibacterial properties assessment, which comprised an antiadhesion assay and a direct contact test. The currently available epoxy resin sealer, $\mathrm{AH}$ Plus, which offers good antibacterial performance and is used clinically, was employed for the control group. All of the test materials were sterilized by ethylene oxide gas exposure prior to the test.

\section{Antiadhesion assay}

Materials solidified in the Teflon mould $(\Phi 5.0 \mathrm{~mm}$ $\times 3 \mathrm{~mm}$ ) were immerged in $1 \mathrm{~mL}$ of a bacterial suspension $\left(10^{6} \mathrm{CFU} / \mathrm{mL}\right)$ for 24 hours. Then, the samples were gently washed with sterilized phosphate buffered saline (PBS) to remove the loose and unattached bacterial cells. After being fixed with $2.5 \%(\mathrm{v} / \mathrm{v})$ glutaraldehyde (Sigma-Aldrich Co., St Louis, MO, USA) for 2 hours, the samples were dehydrated for 10 minutes with each of a series of ethanol solutions $(30 \%, 50 \%, 70 \%, 80 \%, 90 \%, 95 \%$, and $100 \%)$ and dried by using the critical-point method. At the end of this procedure, the samples were coated with gold and viewed via scanning electron microscopy (SEM) (Jeol 6500LV; JEOL, Tokyo, Japan).

\section{Direct contact test}

The direct contact test (DCT), which was developed by Weiss et $\mathrm{al}^{24}$ is an effective method for evaluating the antibacterial activity of root canal sealing materials; this method is based on the turbidimetric determination of bacterial growth in 96-well microtiter plates. The antibacterial activities of the sealers were tested after two different treatments were administered for experimental reliability: samples were used after just curing (designated as fresh samples), and fresh samples were set in a humid atmosphere at $37^{\circ} \mathrm{C}$ for 7 days and washed with PBS before testing; these were designated as 7-d samples.

A 96-well microtiter plate was held vertically, and the side walls of four wells were coated to a height of $3 \mathrm{~mm}$ with each of the mixed test materials by using a cavity liner applicator; these were designated as Group A wells. A $10 \mu \mathrm{L}$ bacterial suspension (approximately $1 \times 10^{6} \mathrm{CFU} / \mathrm{mL}$ ) was placed on the fresh and 7-d samples, each in a different plate, and the plates were maintained in a vertical position in a $37^{\circ} \mathrm{C}$ incubator for 1 hour. This ensured volatilization of the suspension's liquid and direct contact between the bacteria and the sealers.

BHI broth $(230 \mu \mathrm{L})$ was added to each of the wells, and the plates were vortex-mixed for 2 minutes; a $15 \mu \mathrm{L}$ inoculum was then transferred from the A wells to the wells of an adjacent set containing fresh medium $(200 \mu \mathrm{L})$. They were again mixed for 2 minutes, and were referred to as the absence of materials group, or Group B, wells. Namely, the bacteria in the Group B wells came in contact with the material from the Group A wells for 1 hour; they were then incubated without materials. This resulted in two sets of four wells for each tested sealer containing an equal volume of the liquid medium, so that the bacterial growth could be monitored both in the presence and in the absence of the tested material. Two sets of uncoated wells in the same microtiter plate were inoculated with identical volumes of bacterial suspension, and these served as controls. Plates were incubated at $37^{\circ} \mathrm{C}$ in an anaerobic incubator. The bacterial growth in each well was measured at $37^{\circ} \mathrm{C}$ at $650 \mathrm{~nm}$ with a microplate spectrophotometer (PerkinElmer 1420 Multilabel Counter 
VICTOR ${ }^{3 \text { TM}}$; PerkinElmer, Inc., Waltham, MA, USA). The results were recorded once every hour for 8 hours, and then again after 24 hours of incubation.

\section{MTT assay}

The influence of the sealers on the proliferation of L929 murine fibroblasts was evaluated via MTT assay (3-[4,5dimethylthiazol-2-yl]-2,5-diphenyl-2 $H$-tetrazolium bromide; Amresco LLC, Solon, OH, USA). In order to form the leaching liquor, the AH Plus sealers and PU sealers were immersed in Dulbecco's Modified Eagle's Medium (DMEM) at $37^{\circ} \mathrm{C}$ for 48 hours. The L929 cells that were cultured in DMEM for 3 days were seeded $\left(5 \times 10^{4} \mathrm{CFU} / \mathrm{mL}\right)$ in the leaching liquor of AH Plus sealers and in that of PU sealers. The cells were cultured at $37^{\circ} \mathrm{C}$ with $5 \% \mathrm{CO}_{2} / 95 \%$ air atmosphere for 1 day, 3 days, and 7 days. The medium was changed every 2 days. All of the test materials were sterilized by ethylene oxide gas exposure, and the test was performed in triplicate.

\section{Statistical analysis}

The data were expressed as the mean \pm standard deviation (SD). Statistical significance was determined by using SPSS (version 10.0) software (IBM Corporation, Armonk, NY, USA). Multiple comparisons were performed by using Tukey's test, and $P<0.05$ was considered significant.

\section{Results and discussion FTIR analysis}

FTIR spectroscopy is a useful method to analyze chemical species and functional groups in a variety of complex samples. Figure 1 shows the FTIR spectra of PTMEG, IPDI, and the different PU-based components. The intensity of the $\mathrm{OH}$ groups (which peak at 3,475 $\mathrm{cm}^{-1}$ ) in PTMEG decreased after the formation of Pre-PU and the final polymer, PU. The pattern of intensity for the NCO groups (which peak at 2,270 $\mathrm{cm}^{-1}$ ) in IPDI was similar to the pattern of intensity for the $\mathrm{OH}$ groups. Namely, the concentrations of the $\mathrm{OH}$ groups and the $\mathrm{NCO}$ groups dramatically reduced after the prepolymers formed, and those groups were almost totally consumed in the formation of the final PU-based sealer process. The relatively high intensity of the NCO groups in Pre-PU sealers indicates that Component A is an NCO-terminated prepolymer. The reduction of the $\mathrm{OH}$ and NCO groups after mixing Component A with Component B can be attributed to the further polymerization that consumed almost all of the $\mathrm{OH}$ and $\mathrm{NCO}$ groups to form the final products. At the same time, the strength of the peak at $1,718 \mathrm{~cm}^{-1}$ (attributed to the $\mathrm{C}=\mathrm{O}$ vibration) ${ }^{22}$ increased as polymerization proceeded; this also indicates the formation of PU.

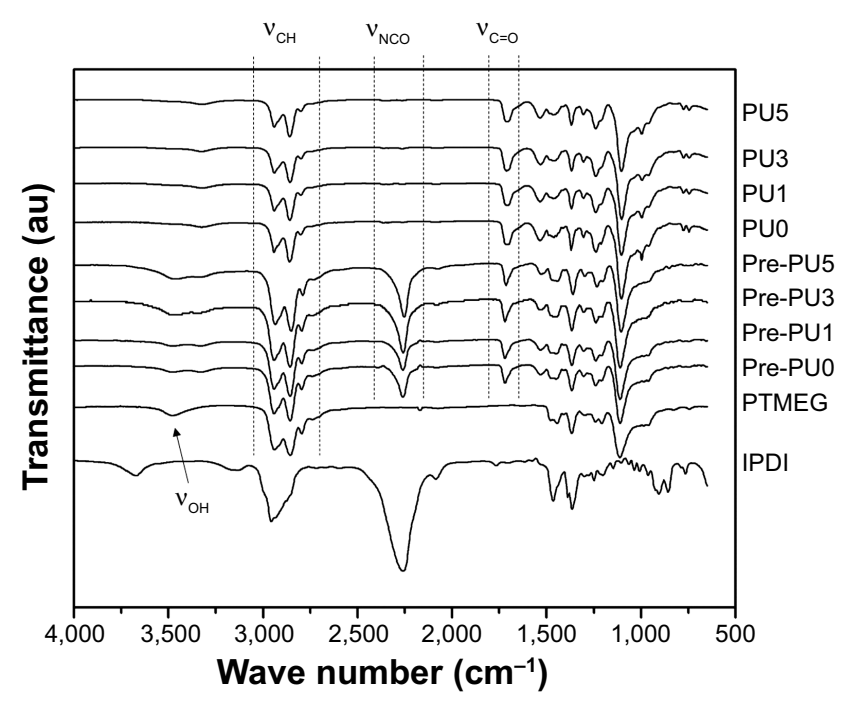

Figure I FTIR spectra of IPDI, PTMEG, and different PU-based composites. Notes: Wave number is denoted by $v$. The names of the tested sealers begin with PU. PU0 is 0 wt\% silver phosphate $\left(\mathrm{Ag}_{3} \mathrm{PO}_{4}\right)$. Similarly, $\mathrm{PUI}$ is I wt\% $\mathrm{Ag}_{3} \mathrm{PO}_{4}$, PU3 is $3 \mathrm{wt} \% \mathrm{Ag}_{3} \mathrm{PO}_{4}$, and PU5 is $5 \mathrm{wt} \% \mathrm{Ag}_{3} \mathrm{PO}_{4}$. For each of these sealers, the corresponding NCO-terminated PU prepolymer begins with the prefix "Pre-". Abbreviations: au, arbitrary units; FTIR, Fourier transform infrared; IPDI, isophorone di-isocyanate; PTMEG, polytetramethylene ether glycol; PU, polyurethane; NCO, isocyanate.

In order to investigate the polymerization process in detail, a series of spectra of as-synthesized PUs was collected at different times (Figure 2). The absorption bands at about $1,718 \mathrm{~cm}^{-1}$ (imide-I) and $725 \mathrm{~cm}^{-1}$ (imide-II) ${ }^{25}$ are characteristic bands of imide bonds, which verifies that the imide groups have been introduced to PUs. The NCO absorption band decreased at approximately $2,300-2,200 \mathrm{~cm}^{-1}$ because of its reaction with the $\mathrm{OH}$ groups. It can be seen that the times when the NCO group were not apparent were 24 hours for PU0, 17 hours for PU1, and 9 hours for both PU3 and PU5. In addition, the decay of the $\mathrm{OH}$ and $\mathrm{NCO}$ groups also demonstrated the degree of conversion of free monomers. Figure 3 shows the decay of the NCO groups with increasing curing time. The integrated peaks of the NCO group areas were calculated to evaluate the degree of NCO conversion against time; these results are listed in Figure 4A. It can be concluded that the pure PU sealer has the lowest degree of monomer conversion, even after 7 hours; more than 30\% of the NCO group in that sealer did not participate in the curing reaction.

However, the degree of NCO conversion was considerably enhanced when $\mathrm{Ag}_{3} \mathrm{PO}_{4}$ incorporation had increased. The data indicated that only about $22 \%, 5 \%$, and $2 \%$ of the NCO groups remained in PU1, PU3, and PU5, respectively, after 7 hours. These results suggest that $\mathrm{Ag}_{3} \mathrm{PO}_{4}$ may serve as a catalyst to promote the high conversion rate of PU-based sealers. 

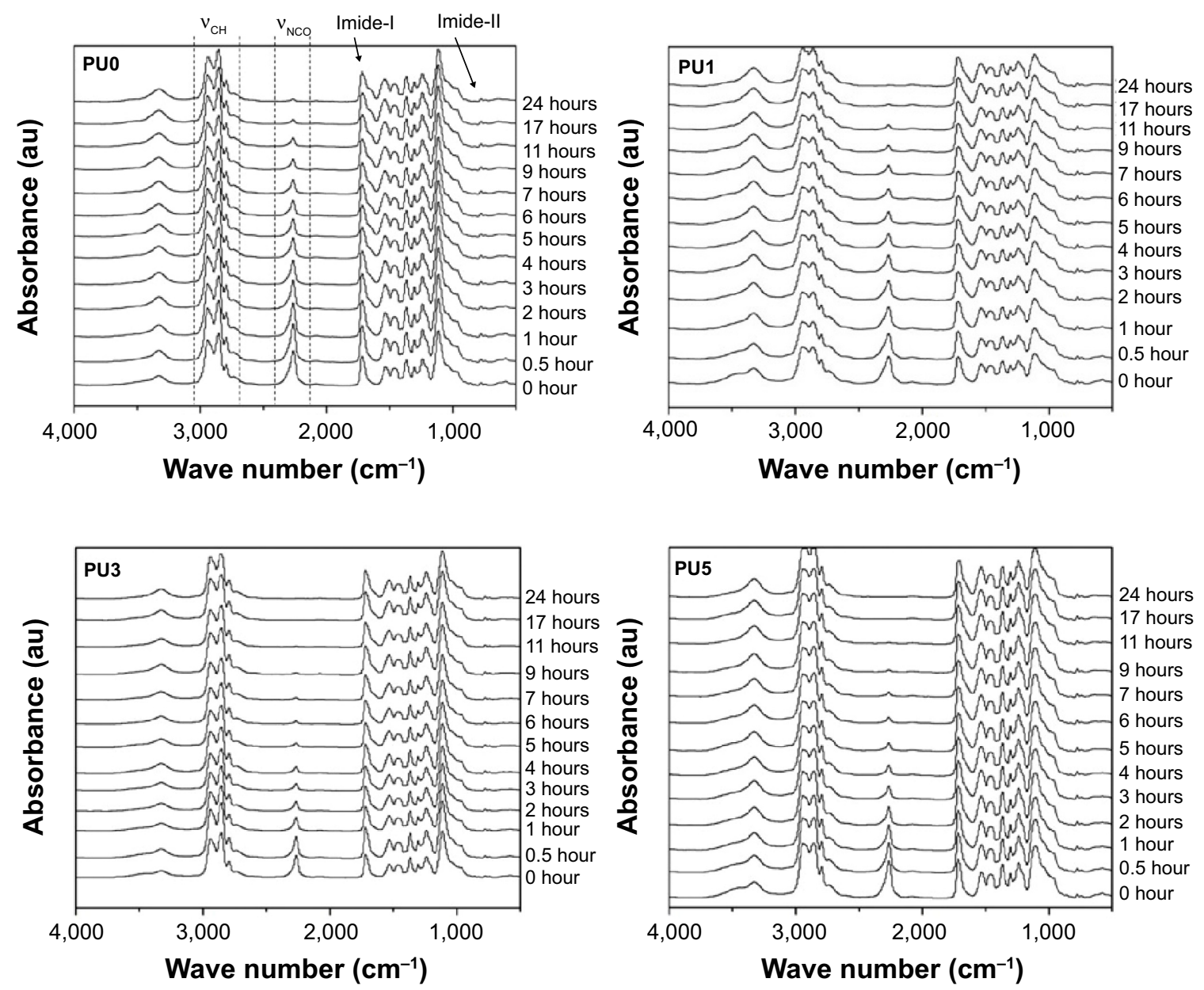

Figure 2 The FTIR spectra of PU-based sealers in zones $500-4,000 \mathrm{~cm}^{-1}$.

Notes: Each PU-based sealer is made from a mixture of Component A and Component B. Component A is an NCO-terminated PU prepolymer. Component B is a mixture of dibutyltin dilaurate, triethanolamine, and PEG. PUO is 0 wt\% silver phosphate $\left(\mathrm{Ag}_{3} \mathrm{PO}_{4}\right)$. Similarly, $\mathrm{PUI}$ is I wt\% $\mathrm{Ag}_{3} \mathrm{PO}_{4}, \mathrm{PU}_{3}$ is 3 wt\% $\mathrm{Ag}_{3} \mathrm{PO}_{4}$, and $\mathrm{PU}$ is 5 wt\% $\mathrm{Ag}_{3} \mathrm{PO}$. Abbreviations: PU, polyurethane; au, arbitrary units; FTIR, Fourier transform infrared; NCO, isocyanate; PEG, polyethylene glycol.

A high degree of NCO group conversion could avoid the cytotoxicity ${ }^{26,27}$ caused by residual free monomers during polymerization. Increasing the degree of conversion not only ensures the elimination of uncured monomers, which may cause adverse biological reactions, but it also results in more favorable mechanical properties, such as surface hardness, flexural strength, and fracture toughness. ${ }^{20,21}$ In addition, inadequate conversion might also weaken the bond to dentin..$^{28}$ According to the FTIR analysis, the novel PU- $\mathrm{Ag}_{3} \mathrm{PO}_{4}$ sealers showed a high degree of conversion, and this may result in lower cytotoxicity after curing in situ.

Chemical reactions that take place during the curing process determine the polymer's morphology. Therefore, it is significant to explore the mechanisms and kinetics of polymerization to understand how the root canal sealers can transition from an injectable gel to a solid. Based on empirical rate laws, the conversion degree can be expressed as a function of curing degree and temperature. ${ }^{23}$
A basic kinetic equation is as follows:

$$
\frac{\mathrm{d} p}{\mathrm{~d} t}=k(T) f(p)
$$

and when presented in isothermal conditions, it is:

$$
\frac{\mathrm{d} p}{\mathrm{~d} t}=A \exp \left[\frac{-E}{\mathrm{RT}}\right] f(p) .
$$

The nth-order kinetics can be expressed as

$$
\frac{\mathrm{d} p}{\mathrm{~d} t}=k_{0}(1-p)^{n}
$$

Here, $k_{0}$ is a constant that is related to the rate constants, which depend on temperature. The parameter is related to the reaction order. Finally, $p$ is the NCO conversion calculated 
A

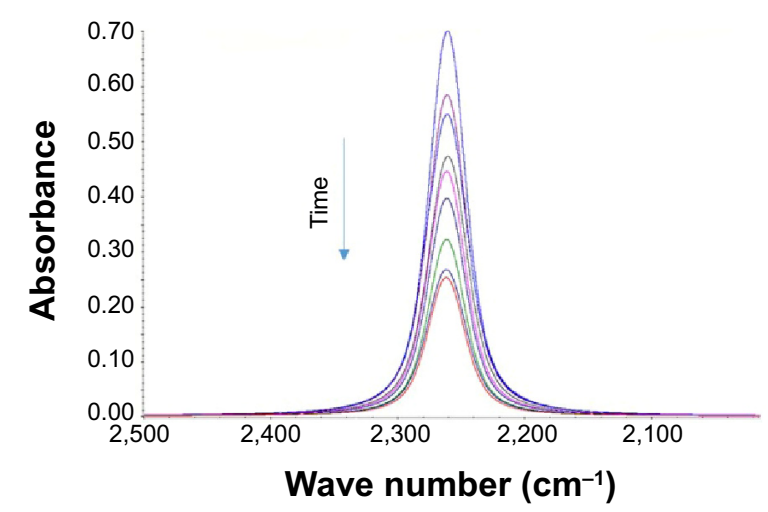

C

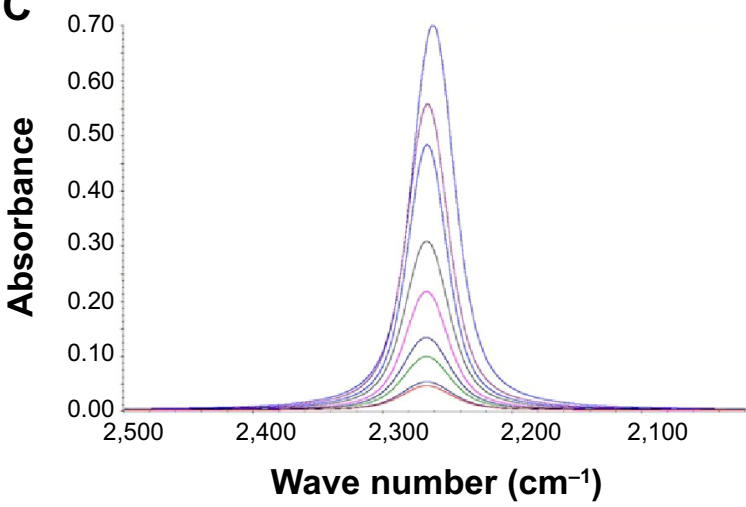

B

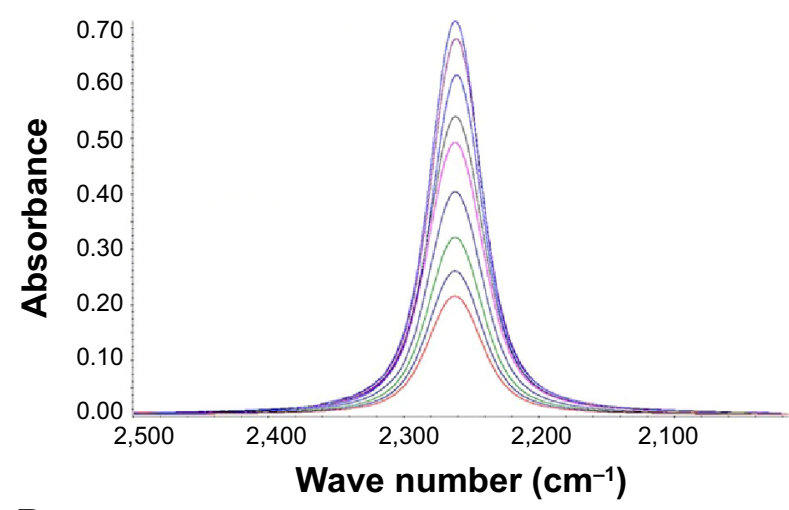

D

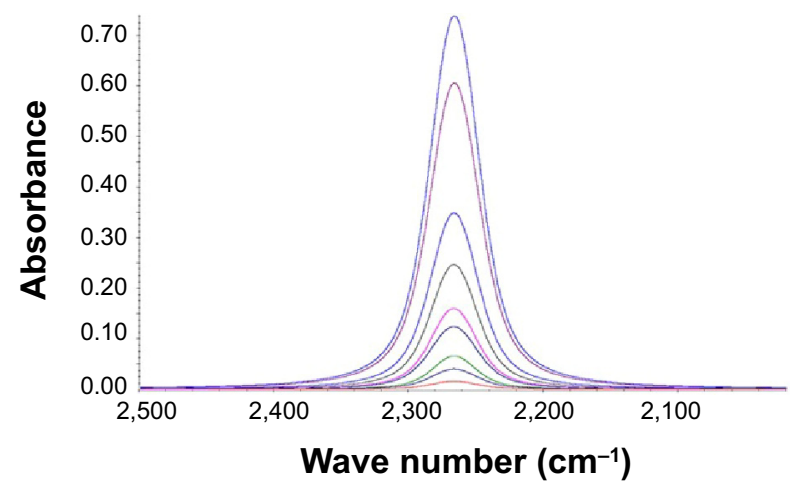

Figure $3 \mathrm{NCO}$ decay in PU-based sealers.

Notes: The variation of NCO decay in FTIR spectra of PU0 (A), PUI (B), PU3 (C) and PU5 (D) against cure time: 0, 30, 60, I20, I80, 240, 300, 360, and 420 minutes. The names of the tested sealers begin with PU. PU0 is 0 wt\% silver phosphate $\left(\mathrm{Ag}_{3} \mathrm{PO}_{4}\right)$. Similarly, $\mathrm{PUI}$ is I wt\% $\mathrm{Ag}_{3} \mathrm{PO}_{4}, \mathrm{PU3}$ is 3 wt\% $\mathrm{Ag}_{3} \mathrm{PO}$, and $\mathrm{PU} 5$ is 5 wt\% $\mathrm{Ag}_{3} \mathrm{PO}$. Abbreviations: NCO, isocyanate; PU, polyurethane; FTIR, Fourier transform infrared.

by equation 2. This method is based on the search of a parameter, n, so as to obtain a linear relationship between the experimental and theoretical data.

$$
\begin{aligned}
& \text { If } \mathrm{n}=1, \ln (1-p)=-k_{0} t+C . \\
& \text { If } \mathrm{n}=2, \frac{1}{(1-p)}=k_{0} t+C . \\
& \text { If } \mathrm{n}=3, \frac{1}{(1-p)^{2}}=k_{0} t+C .
\end{aligned}
$$

Figure 4 shows the curves that were calculated by using the three equations $(6,7,8)$ that were applied in the curing process, and the fitting results are summarized in Table 1. It is evident that all of the PU-based sealers support the first-order reaction. However, this kinetic approach is not suitable for evaluating the entire curing process. Since the curing reaction had proceeded, the liquid resin slowly became solid; in response, its reaction mechanism changed. In fact, at the end of the reaction, the rate was controlled by diffusion rather than by chemical reactions.

\section{Physical properties}

Physical properties such as setting time, film thickness, and solubility were significant measurements that were used to evaluate the properties of endodontic sealers. According to ISO $6876: 2001(\mathrm{E})$, a series of technical tests has been systematically performed to assess the physical properties of the endodontic sealers.

Table 2 shows the physical properties of the AH Plus sealer and the PU-based sealers. The setting time shortened with the increase of $\mathrm{Ag}_{3} \mathrm{PO}_{4}$ content in the PU sealers. However, film thickness and solubility increased with the rising concentration of $\mathrm{Ag}_{3} \mathrm{PO}_{4}$. These properties make the fabricated PU-based sealers better than the positive control (AH Plus), and, with the exception of the film thickness of PU5, these properties allow the fabricated PU-based sealers to satisfactorily meet ISO standards.

The setting time for the standard has not been prescribed for specific restrictions; however, it should be long enough for convenient manipulation in clinical settings. The setting times of the PU sealers with different proportions of $\mathrm{Ag}_{3} \mathrm{PO}_{4}$ are just shorter than the setting time of AH Plus, and these 
A

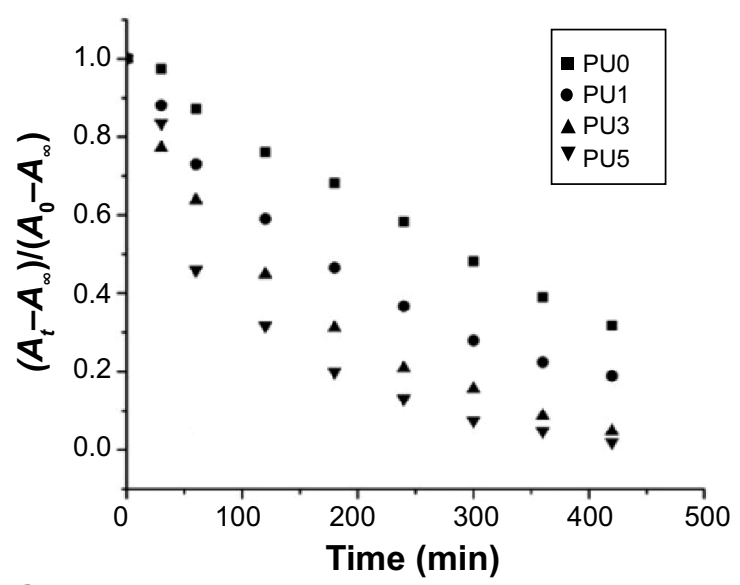

C

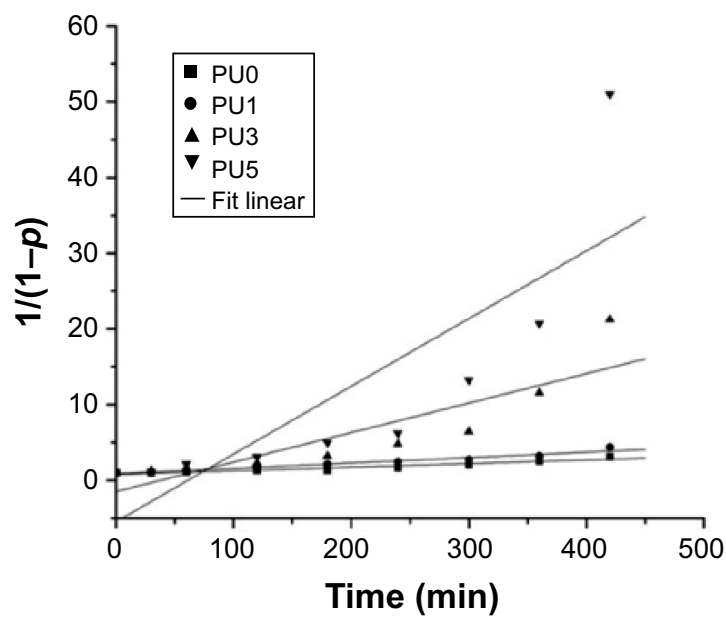

B

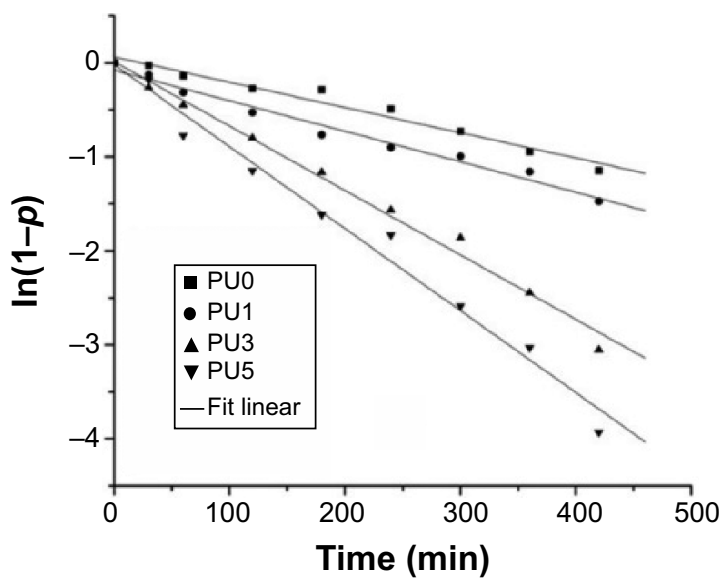

D

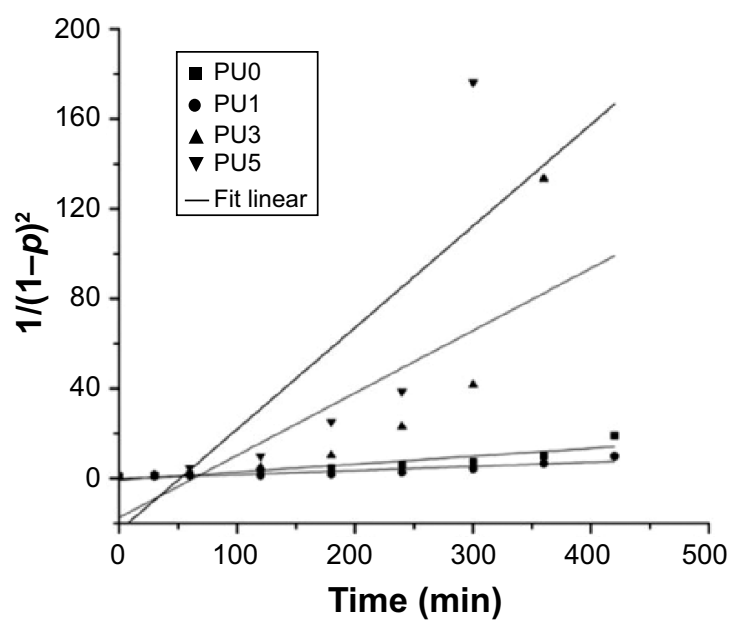

Figure 4 Kinetics of $\mathrm{NCO}$ conversion.

Notes: Changes of NCO at different times during the curing process (A). The relationship between p and the curing time of PU-based sealers (B-D). The conversion of $\mathrm{NCO}$ during polymerization is represented by $p$. The integrated absorption area at the initial time is represented by $A_{0}$. The integrated absorption area at time $t$ during the process is represented by $A_{t}$. The final integrated absorption area is represented by $A_{\infty}$. The names of the tested sealers begin with PU. PU0 is 0 wt\% silver phosphate $\left(\mathrm{Ag}_{3} \mathrm{PO}_{4}\right)$. Similarly, $\mathrm{PUI}$ is I wt\% $\mathrm{Ag}_{3} \mathrm{PO}_{4}, \mathrm{PU} 3$ is $3 w t \% \mathrm{Ag}_{3} \mathrm{PO}_{4}$, and $\mathrm{PU} 5$ is $5 w t \% \mathrm{Ag}_{3} \mathrm{PO}_{4}$.

Abbreviations: NCO, isocyanate; $\mathrm{PU}$, polyurethane.

times can meet the ISO standard. It also can be seen from the results that the higher the content of $\mathrm{Ag}_{3} \mathrm{PO}_{4}$ incorporated in the PU sealer, the shorter the curing time. Thus, it can be inferred that $\mathrm{Ag}_{3} \mathrm{PO}_{4}\left(\right.$ or $\left.\mathrm{Ag}^{+}\right)$has a positive catalytic effect on polymerization. Film thickness reflects the fluidity of the endodontic sealers, which is an important feature for assessing the material's capacity to penetrate into irregularities and accessory canals. ${ }^{29} \mathrm{We}$ can conclude from the results of the thickness tests that the PU0, PU1, and PU3 sealers have good fluidity. However, the PU5 sealer does not meet the ISO standard. This may be attributed to the catalysis of $\mathrm{Ag}^{+}$, which leads to the curing of PU sealers before they can fully spread. On the other hand, excessive fluidity may increase the risk of extravasation and cytotoxicity. Hence, the appropriate setting time and fluidity of endodontic sealers are critical factors for successful endodontic treatment. The ideal setting time and fluidity of the fabricated PU-based sealers can be explained by the two-component (A and $\mathrm{B}$ ) design, in which Component $\mathrm{A}$ is an NCO-terminated PU prepolymer with good fluidity, and component $\mathrm{B}$ is a liquid mixture. The mixture of components A and B has good fluidity and can be injectable during an initial period; it then gradually solidifies at body temperature with the reaction between $\mathrm{NCO}$ in Component $\mathrm{A}$ and $\mathrm{OH}$ in Component $\mathrm{B}$. Another important requirement for dental material that is used in permanent treatment, especially when exposed to a host environment for a prolonged period, is its resistance to solubility and degradation. According to the ISO standard, solubility is the loss of mass that occurs during a period of immersion in deionized water. The results showed that all of the fabricated PU-based sealers can meet 
Table I Rate constants and fitting results for the curing process of PU

\begin{tabular}{llllll}
\hline Order & Parameter & PU0 & PUI & PU3 & PU5 \\
\hline First-order & $k_{0}$ & 0.003246 & -0.002688 & -0.008720 & -0.006857 \\
& $C$ & -0.078792 & 0.062712 & -0.019953 & 0.012787 \\
Second-order & $R^{2}$ & 0.977269 & 0.961936 & 0.980816 & 0.988903 \\
& $k_{0}$ & 0.007086 & 0.004781 & 0.089402 & 0.038921 \\
& $C$ & 0.882516 & 0.785163 & -5.457348 & 0.470421 \\
Third-order & $R^{2}$ & 0.945718 & 0.895708 & 0.642805 & 0.739532 \\
& $k_{0}$ & 0.035134 & 0.018554 & 0.452174 & -17.462346 \\
& $C$ & -0.653286 & -0.195858 & -23.310087 & 0.594581 \\
\hline
\end{tabular}

Notes: The constant $k_{0}$ is related to the rate constants, which depend on temperature. $R^{2}$ is the correlation coefficient. The strength of the linear correlation between points increases proportionally as $R^{2}$ gets closer to I. AH Plus is the commercial sealer that was used as a positive control. The names of the tested sealers begin with PU. PU0 is 0 wt\% silver phosphate $\left(\mathrm{Ag}_{3} \mathrm{PO}_{4}\right)$. Similarly, $\mathrm{PUI}$ is $\mathrm{I}$ wt\% $\mathrm{Ag}_{3} \mathrm{PO}_{4}, \mathrm{PU} 3$ is $3 \mathrm{wt} \% \mathrm{Ag}_{3} \mathrm{PO}_{4}$, and $\mathrm{PU} 5$ is $5 \mathrm{wt} \% \mathrm{Ag}_{3} \mathrm{PO}_{4}$.

Abbreviations: $\mathrm{C}$, constant; $\mathrm{PU}$, polyurethane.

the requirements of the ISO standard. The solubility of the fabricated PU-based sealers increases with $\mathrm{Ag}_{3} \mathrm{PO}_{4}$ incorporation; this correlation may be attributed to more $\mathrm{Ag}_{3} \mathrm{PO}_{4}$ on the surface of the material dissolving in water.

The shrinkage of the sealer will lead to gaps and channels, which may permit oral bacterial to pass through. As such, proper expansion of sealers after curing is necessary and preferred. However, because of stress, excess expansion in a narrow root canal may lead to a root fracture. ${ }^{22}$ In fact, none of the tested sealers listed in Table 2 meet the ISO standard in this regard. However, the risk of root fracture is related to tangential strain, which is affected by the elastic modulus of dentin and the root canal sealer, as well as by the expansion of the material. Thus, a sealer with a low elastic modulus has a lower threat to dentin than one with a high modulus. In fact, the Young's Modulus for dentin is $13.2 \pm 4.0 \mathrm{GPa} .^{20}$ The moduli for PU-based sealers are 4.32 $\pm 0.21 \mathrm{MPa}$

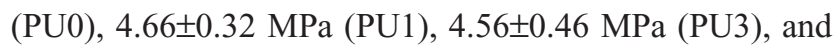
$4.78 \pm 0.48 \mathrm{MPa}$ (PU5). Therefore, it is reasonable to conclude that the low moduli of PU-based sealers can reduce the amount of damage to root dentin that is generated by volume expansion. On the other hand, the limited expansion of PU-based sealers after curing can help seal the root canal completely. From the evaluations described above, a conclusion can be drawn in that the physical properties of
PU0, PU1, and PU3 are perfectly consistent with the requirements of a root canal sealer.

\section{Antibacterial properties}

\section{Antibacterial adhesion assay}

S. mutans, commonly isolated from caries lesions and considered to be the primary species associated with dental caries, ${ }^{1,30}$ has been widely used to test the antimicrobial activity of dental restorative materials. ${ }^{31}$ Therefore, S. mutans was employed to evaluate the antibacterial properties of the novel PU-based root canal sealers via antiadhesion assay and DCT.

Figure 5 shows the antibacterial adhesion efficacy viewed by SEM. Each of the PU sealers was immersed in a bacterial suspension for 24 hours. Compared with the other PU sealers, the one made from pure PU (Figure 5A) showed inferior antiadhesion ability against $S$. mutans, as indicated by the fact that $S$. mutans on the surface were confluent and formed a dense network. However, with the increase of $\mathrm{Ag}_{3} \mathrm{PO}_{4}$ incorporated into the PU sealers, the antiadhesive ability against $S$. mutans is much stronger. Only a few bacteria were observed on the surface of the PU3, PU5, and AH Plus sealers in the form of single or small clumps.

Bacterial adhesion is essential for the colonization of oral bacteria. The prevention of microbial adhesion to the implant surface would slow the process of colonization and

Table 2 Physical properties of AH Plus and of PU-based sealers

\begin{tabular}{lllllll}
\hline & ISO standards & AH Plus & PU0 & PUI & PU3 & PU5 \\
\hline Setting time (minutes) & $\leq 4,320$ & $486 \pm 21^{*}$ & $422 \pm 17^{\wedge}$ & $408 \pm 17^{\#}$ & $313 \pm 20^{\$}$ & $250 \pm 16^{\circledR}$ \\
Film thickness $(\mu \mathrm{m})$ & $\leq 50$ & $44.70 \pm 1.20^{*}$ & $29.80 \pm 3.27^{\wedge}$ & $32.44 \pm 1.78^{\wedge}$ & $37.21 \pm 2.7 I^{\$}$ & $52.19 \pm 1.62^{\&}$ \\
Solubility $(\%)$ & $\leq 3$ & $0.41 \pm 0.18^{*}$ & $0.13 \pm 0.07^{\wedge}$ & $0.23 \pm 0.09^{\wedge}$ & $0.34 \pm 0.11^{*}$ & $0.41 \pm 0.12^{*}$ \\
Dimensional change (\%) & Expansion $\leq 0.1 \%$ & $1.37 \pm 0.68^{*}$ & $1.83 \pm 0.4 I^{\wedge}$ & $1.88 \pm 0.32^{\#}$ & $1.84 \pm 0.52^{\wedge}$ & $1.83 \pm 0.26^{\wedge}$ \\
\hline
\end{tabular}

Notes: The names of the tested sealers begin with PU. PU0 is 0 wt\% silver phosphate $\left(\mathrm{Ag}_{3} \mathrm{PO}_{4}\right)$. Similarly, $\mathrm{PUI}$ is I wt $\mathrm{Ag}_{3} \mathrm{PO}_{4}, \mathrm{PU}$ is 3 wt $\% \mathrm{Ag}_{3} \mathrm{PO}_{4}$, and $\mathrm{PU} 5$ is 5 wt\% $\mathrm{Ag}_{3} \mathrm{PO}_{4}$. $\mathrm{AH}$ Plus is the commercial sealer that was used as a positive control. Values followed by different superscript symbols in each row differ significantly and represent the qualitative difference for the values.

Abbreviation: PU, polyurethane. 

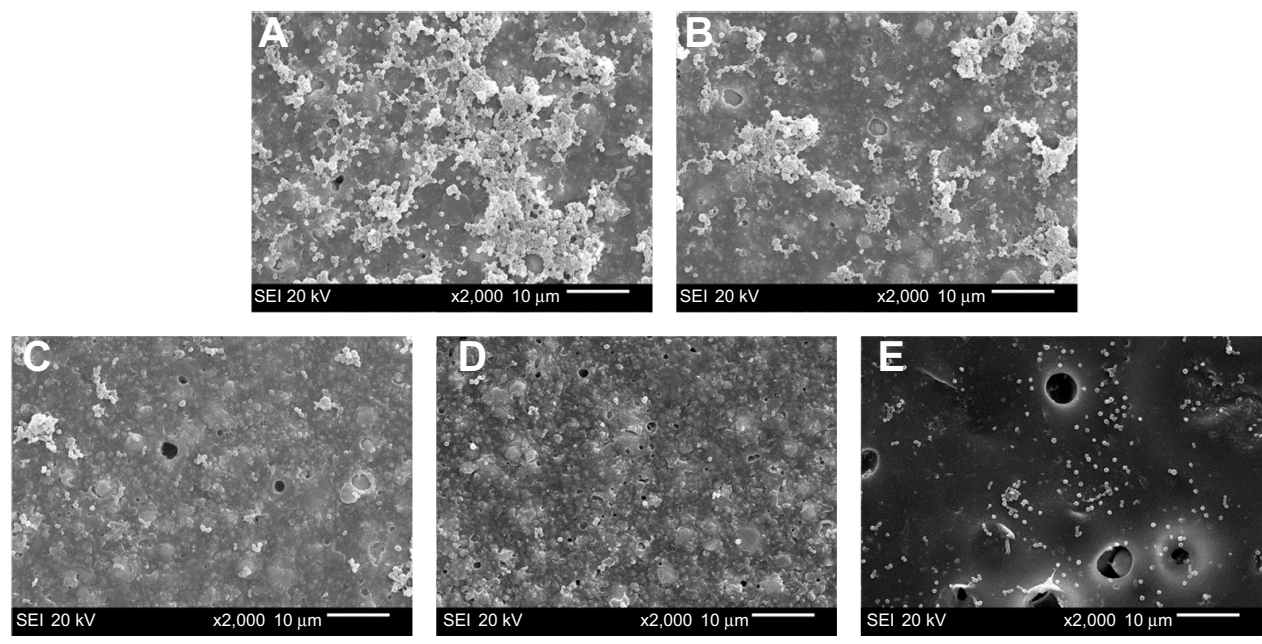

Figure 5 SEM images of bacterial adhesion on PU-based sealers.

Notes: Images of PU0 (A), PUI (B), PU3 (C), PU5 (D), and AH Plus (E) sealers after 24 hours of incubation with Streptococcus mutans. The names of the tested sealers begin with PU. PU0 is 0 wt\% silver phosphate $\left(\mathrm{Ag}_{3} \mathrm{PO}_{4}\right)$. Similarly, $\mathrm{PUI}$ is I wt\% $\mathrm{Ag}_{3} \mathrm{PO}_{4}, \mathrm{PU} 3$ is 3 wt $\mathrm{Ag}_{3} \mathrm{PO}_{4}$, and $\mathrm{PU} 5$ is 5 wt\% $\mathrm{Ag}_{3} \mathrm{PO}$. $\mathrm{AH} \mathrm{Plus}$ is the commercial sealer that was used as a positive control.

Abbreviations: SEM, scanning electron microscopy; PU, polyurethane.

thus lead to a more favorable therapeutic outcome. ${ }^{16}$ All of the sealers were tested for their antiadhesive effects by using an in situ adhesion assay to determine whether the sealers inhibit adhesion by blocking $S$. mutans adhesion on the test materials. However, most studies did not attempt to determine the adhesion ability of root canal sealers, despite its significance. All of the tested materials that were compared with pure PU sealers were able to inhibit the adhesion of $S$. mutans strains on the surface to different degrees, and the results suggest that the concentration of an antibacterial agent plays an important role. A sufficient antibacterial agent could provide good antimicrobial capacities and reduce the risk of reinfection in the root canal treatment process. However, higher concentrations of an antibacterial agent could induce severe cytotoxicity. Therefore, a proper concentration of $\mathrm{Ag}_{3} \mathrm{PO}_{4}$ incorporation should be selected.

\section{DCT}

Since the experimental technique, the time, or the ingredients of the tested materials affect the results of microbiological studies, it has been proposed that more than one assaying method be used in the process of evaluating the antibacterial properties of dental materials. As such, DCT was also used to assess the antibacterial abilities of the fabricated sealers.

The results of the DCT for freshly mixed sealers and 7-day sealers are shown in Figure 6. Each point on the curve is the mean of three absorbance measurements for a set of four wells for a particular time, and the bar represents the SD.

In Group A wells, where bacteria grew in the presence of the tested material, the fresh samples except for PU0 showed almost complete inhibition of bacterial growth. For the 7-day samples, the PU3, PU5, and AH Plus sealers exhibited complete inhibition of bacterial proliferation. However, the PU1 sealer showed a short antibacterial effect before 4 hours, and then the bacteria proliferated rapidly for up to 24 hours, although the absorbance value was lower than that of the PU0 sealer and that of the control group.

In the Group B wells, the results were not totally different from those of Group A. However, unlike in Group A, the PU1 and AH Plus sealers caused 3-hour and 6-hour delays, respectively, in the growth curves of the 7-day samples. The results for the PU0 sealer were similar to those for the negative control group; this finding suggests that the pure PU sealer possesses little antibacterial activity.

From the results of the DCT test, all of the freshly mixed test sealers except for PU0 were equally effective at inhibiting bacterial growth and exerting bactericidal effects. Only the PU3 and PU5 sealers still exerted antibacterial activity after being mixed and set in a humid atmosphere at $37^{\circ} \mathrm{C}$ for 7 days. For the 7-day samples, AH Plus completely inhibited bacterial growth only when the bacteria were incubated in the presence of the sealer (Group A wells); bacterial growth was not completely inhibited in the absence of the test sealer (Group B wells). This finding indicated that the 7-day samples of AH Plus were not effective in killing all S. mutans organisms after short-term (1 hour) direct contact with the materials. The possible reasons for this may include the loss of some antibiotic components in the PU1 and AH Plus samples, especially on the surface, after both treatment in a humid atmosphere for 7 days and washing by PBS, which 
A

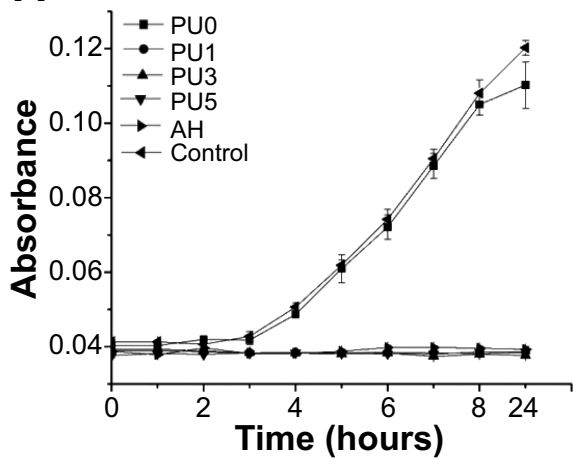

C

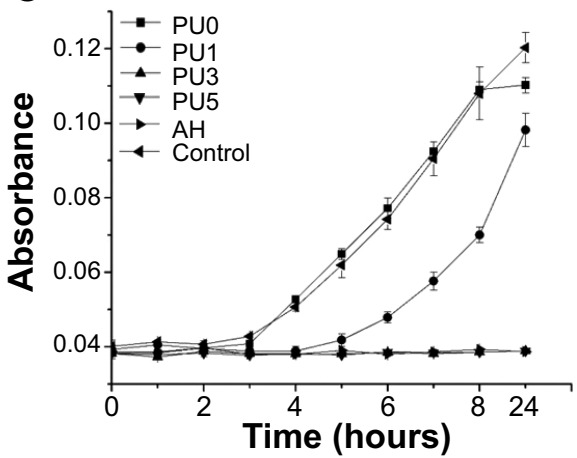

B
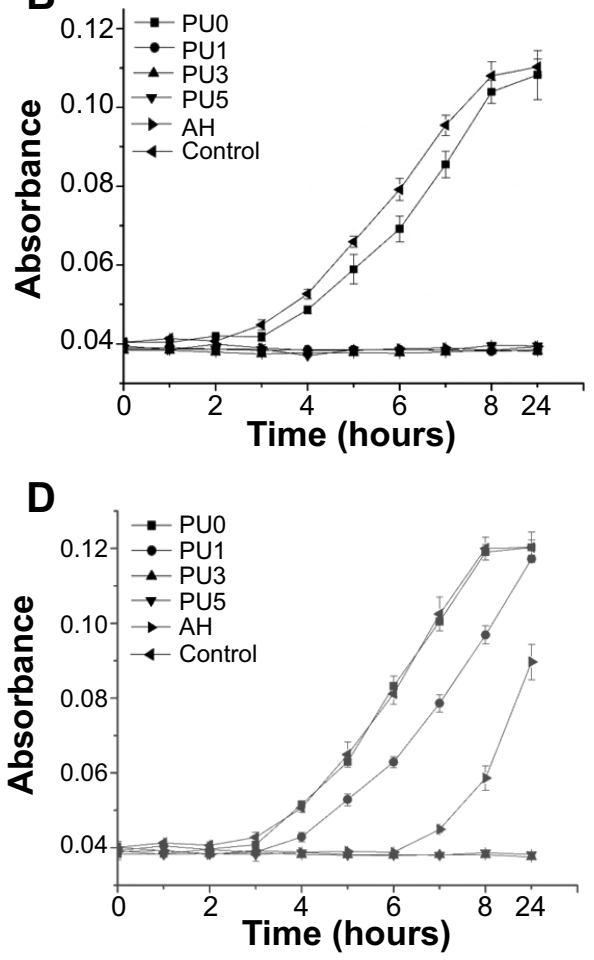

Figure 6 DCT results of fresh samples and 7-day samples.

Notes: Turbidimetric readings for fresh samples (A and B) and 7-day samples (C and D) for 24 hours. The names of the tested sealers begin with PU. PU0 is 0 wt\% silver phosphate $\left(\mathrm{Ag}_{3} \mathrm{PO}_{4}\right)$. Similarly, $\mathrm{PUI}$ is I wt\% $\mathrm{Ag}_{3} \mathrm{PO}_{4}, \mathrm{PU} 3$ is $3 \mathrm{wt} \% \mathrm{Ag}_{3} \mathrm{PO}_{4}$, and $\mathrm{PU} 5$ is $5 \mathrm{wt} \% \mathrm{Ag}_{3} \mathrm{PO}_{4}$. AH Plus is the commercial sealer that was used as a positive control. Part $(\mathbf{A})$ and $(\mathbf{C})$ represent the bacteria that grew in the presence of the tested material, however, part (B) and (D) represent the bacteria that were incubated without the tested material. Namely, the bacteria in the part B came in contact with the material from part (A) for I hour, then incubated without tested material. Similarly, the bacteria in the part (D) came in contact with the material from part (B) for I hour, then incubated without tested material.

Abbreviations: DCT, direct contact test; PU, polyurethane.

cannot diffuse sufficient antibacterial components to inhibit bacterial proliferation. Nonetheless, 7-day samples of PU3 and PU5 still present excellent antibacterial ability, suggesting that their antibacterial persistence is better than that of PU1 and the positive control (commercial AH Plus).

The antibacterial properties of the PU-based sealers can be attributed to the silver ions located on the surface and/or released from the material of the incorporated $\mathrm{Ag}_{3} \mathrm{PO}_{4}$. It has been reported that silver ions have long been known to have strong inhibitory and bactericidal effects, and they also offer a broad antibacterial spectrum. ${ }^{32}$ The effects of silver ions on bacteria may be complicated, and the mechanism for this effect is still not fully understood. In fact, many studies have reported that $\mathrm{Ag}^{+}$shows powerful antibacterial activity and exerts similar toxicity against bacteria under both aerobic and anaerobic conditions. ${ }^{33}$ However, its toxicity to human cells is considerably lower than to bacteria. ${ }^{34}$ It is generally believed that heavy metals react with proteins by combining the thiol (SH) groups, which leads to the inactivation of proteins. ${ }^{35}$ The SH group is an important group of proteins that is responsible for enzymatic activity. Therefore, the entrance of silver into bacterial cells may lead to the deposition of proteins within the cells. It is assumed that the interaction of $\mathrm{Ag}^{+}$with the $\mathrm{SH}$ groups plays an essential role in bacterial inactivation. ${ }^{36}$ In addition, it is known that the replication of DNA molecules is effectively conduced only when DNA molecules are in a relaxed state. In a condensed form, DNA molecules lose their replication abilities. ${ }^{35}$ The released silver ions penetrate the cell wall, enter into the cells, and subsequently turn DNA into a condensed form and restrain DNA replication. All of these phenomena lead to damage or even death of the microorganisms. This multilevel antimicrobial mode of silver ions ensures that resistance cannot be easily acquired by single-point mutations and can endow an $\mathrm{Ag}_{3} \mathrm{PO}_{4}$-containing PU-based self-curing sealer with a broad antibacterial spectrum. In view of the high prevalence of facultative anaerobes and anaerobes in unsuccessful endodontic therapy, the antibacterial activity of root canal sealers on these microorganisms may help to eliminate residual microorganisms that are unaffected by both chemomechanical preparation and intracanal medication and may help control infection. ${ }^{37}$ The PU-based self-curing sealers 


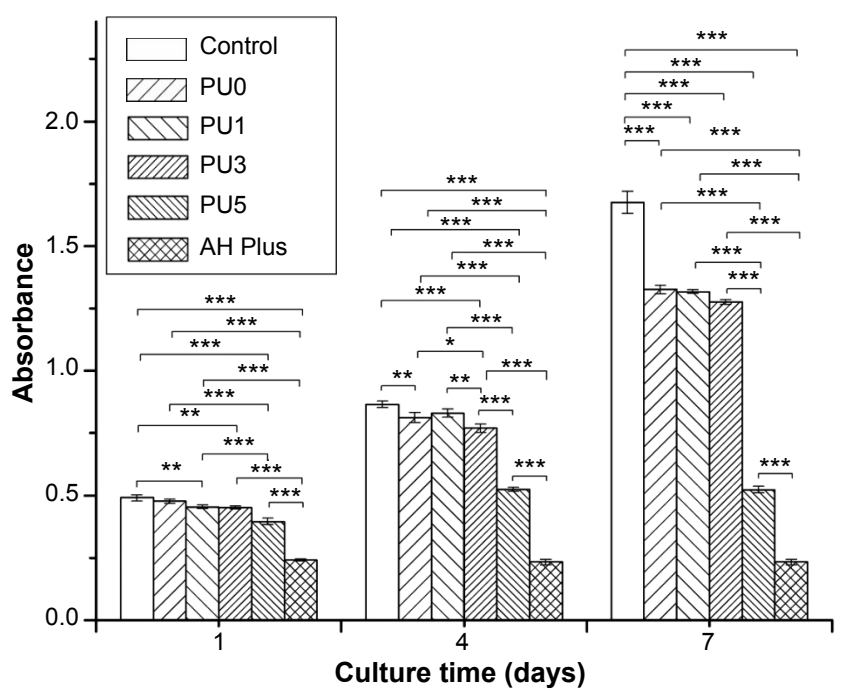

Figure 7 MTT assays of L929 murine fibroblasts.

Notes: MTT assays of L929 murine fibroblasts cultured with the leaching liquor of each of the PU-based sealers, the leaching liquor of $\mathrm{AH}$ Plus, and the leaching liquor of the control group for I day, 4 days, and 7 days. The names of the tested sealers begin with PU. PUO is 0 wt\% silver phosphate $\left(\mathrm{Ag}_{3} \mathrm{PO}_{4}\right)$. Similarly, $\mathrm{PUI}$ is I wt\% $\mathrm{Ag}_{3} \mathrm{PO}_{4}, \mathrm{PU} 3$ is $3 \mathrm{wt} \% \mathrm{Ag}_{3} \mathrm{PO}_{4}$, and $\mathrm{PU} 5$ is $5 \mathrm{wt} \% \mathrm{Ag}_{3} \mathrm{PO}_{4}$. $\mathrm{AH}$ Plus is the commercial sealer that was used as a positive control. Statistical significance is denoted as follows: *** is significant at $P<0.001$; ** is signficant at $P<0.01$; and * is significant at $P<0.05$.

Abbreviations: MTT, 3-[4,5-dimethylthiazol-2-yl]-2,5-diphenyl-2H-tetrazolium bromide; PU, polyurethane.

with good antibacterial ability reported in current study hold promise for use in the field of root canal fillings.

\section{Cytocompatibility}

As shown in Figure 7, the proliferation of L929 cells in PU0, PU1, PU3, and the control groups increased with culture time. However, the cells almost ceased to grow 4 days later in PU5, and there seemed to be no proliferation in the AH Plus group. In fact, there was no significant difference in cell proliferation during the initial culture period among PU0, PU1, and PU3. However, 4 and 7 days later, the cell viability of PU3 was slightly lower than the viabilities of both PU0 and of PU1, but it was much higher than those of both PU5 and of the AH Plus group.
According to the US Pharmacopeia (USP) XXII and National Formulary (NF) XVII, the cell's relative growth rate (RGR) can be expressed as the following formula:

$$
\mathrm{RGR}=\frac{\mathrm{A}}{\mathrm{B}} \times 100 \%
$$

in which $\mathrm{A}$ and $\mathrm{B}$ are the average absorbances of the samples and the control groups, respectively. The RGRs and their associated cytotoxicity ranks are as follows: $\geq 100 \%, 0$; between $75 \%-99 \%, 1$; between $50 \%-74 \%, 2$; between $25 \%-49 \%, 3$; between $1 \%-24 \%, 4$; and $0 \%, 5$. Generally, ranks 0 and 1 are qualified; namely, they are not apparently threatening to cells. If the rank is 2, the cell morphology should be analyzed to introduce a comprehensive evaluation; however, the rest of the three ranks are considered to be greatly cytotoxic. The RGRs were calculated and listed in Table 3. The results show that the cytotoxicity ranks of the PU0, PU1, and PU3 sealers are 1 for 7 days of incubation, which means that these fabricated sealers are low or nontoxic for the L929 fibroblasts. Conversely, the PU5 and the AH Plus are severely toxic to the L929 cells.

For dental resin, unbound free monomers are correlated with cytotoxicity on pulp and gingival cells. ${ }^{38,39}$ Thus, it can be inferred that the polymerization conversion of root canal sealers may be considered to be directly responsible for their cytotoxicity. The antibacterial effect of the resin-based sealer, AH Plus, may be related to bisphenol diglycidyl ether, which was previously identified as a mutagenic component of the resin-based material. In addition, it has been reported that the material may release traces of monomer or even formaldehyde,${ }^{40}$ which is often found in trace amounts in polymeric materials. These components make the resin-based sealers antibacterial. However, these powerful antibacterial ingredients may be threatening to the cells. The good cytocompatibility of the PU0, PU1, and PU3 sealers, as revealed by MTT and RGR assessments, may

Table 3 Various properties of the samples after 7 days of incubation

\begin{tabular}{llll}
\hline & Average absorbance (mean \pm SD) & Cell relative growth rate (\%) & Cytotoxicity level \\
\hline PU0 & $1.326 \pm 0.017$ & 96.51 & 1 \\
PUI & $1.317 \pm 0.007$ & 95.85 & 1 \\
PU3 & $1.275 \pm 0.010$ & 92.79 & 1 \\
PU5 & $0.523 \pm 0.013$ & 38.06 & 3 \\
AH Plus & $0.237 \pm 0.012$ & 17.24 & 4 \\
Control & $1.374 \pm 0.045$ & 100.0 & 0 \\
\hline
\end{tabular}

Notes: The names of the tested sealers begin with PU. PU0 is 0 wt\% silver phosphate $\left(\mathrm{Ag}_{3} \mathrm{PO}_{4}\right)$. Similarly, $\mathrm{PUI}$ is I wt\% $\mathrm{Ag}_{3} \mathrm{PO}, \mathrm{PU}_{3}$ is 3 wt\% $\mathrm{Ag}_{3} \mathrm{PO}$, and $\mathrm{PU} 5$ is 5 wt\% $\mathrm{Ag}_{3} \mathrm{PO}_{4}$. AH Plus is the commercial sealer that was used as a positive control.

Abbreviations: PU, polyurethane; SD, standard deviation. 
be correlated to the high degree of monomer conversion. However, PU5 exhibited the worst degree of cytocompatibility, in spite of having the highest degree of conversion, which suggests that the high content of silver ions in the PU sealer will also weaken its cytocompatibility. It can thus be concluded that both a high degree of conversion and a suitable silver ion content are significant for the cytocompatibility of PU sealers.

\section{Conclusion}

In summary, the current study developed a series of injectable PU-based self-curing antibacterial sealers by incorporating different concentrations of $\mathrm{Ag}_{3} \mathrm{PO}_{4}$. The fabricated antibacterial PU-based sealers can achieve a high conversion rate in a short amount of time, and the incorporated $\mathrm{Ag}_{3} \mathrm{PO}_{4}$ may serve as a catalyst to promote the high conversion of NCO; both of these properties could help prevent the cytotoxicity caused by residual free monomers. Meanwhile, $\mathrm{Ag}^{+}$released from the PU sealers could impart excellent antibacterial activity to commonly existing oral bacteria. The fabricated PU sealer with the $3 \mathrm{wt} \%$ concentration of $\mathrm{Ag}_{3} \mathrm{PO}_{4}, \mathrm{PU} 3$, combines good physicochemical properties, antimicrobial properties, and cytocompatibility and thus holds promising applications in the field of root canal filling.

\section{Acknowledgments}

The authors acknowledge support for this research from the China 863 project (2013AA032203, 2011AA030102), the Outstanding Young Scholar Fund of Sichuan University (2014SCU04A20) and the NSFC fund (31370971). English-language editing of this manuscript was provided by Journal Prep.

\section{Disclosure}

The authors report no conflicts of interest in this work.

\section{References}

1. Gjorgievska E, Apostolska S, Dimkov A, Nicholson JW, Kaftandzieva A. Incorporation of antimicrobial agents can be used to enhance the antibacterial effect of endodontic sealers. Dent Mater. 2013;29(3):e29-e34.

2. Pizzo G, Giammanco GM, Cumbo E, Nicolosi G, Gallina G. In vitro antibacterial activity of endodontic sealers. J Dent. 2006;34(1):35-40.

3. Möller ÅJ, Fabricius L, Dahlén G, Sundqvist G, Happonen RP. Apical periodontitis development and bacterial response to endodontic treatment. Experimental root canal infections in monkeys with selected bacterial strains. Eur J Oral Sci. 2004;112(3):207-215.

4. Sundqvist G, Figdor D. Life as an endodontic pathogen. Endod Topics. 2003;6(1):3-28.

5. Chen F, Liu C, Mao Y. Bismuth-doped injectable calcium phosphate cement with improved radiopacity and potent antimicrobial activity for root canal filling. Acta Biomater. 2010;6(8):3199-3207.

6. Siqueira JF Jr. Microbial causes of endodontic flare-ups. Int Endod J. 2003;36(7):453-463.
7. Gesi A, Raffaelli O, Goracci C, Pashley DH, Tay FR, Ferrari M. Interfacial strength of Resilon and gutta-percha to intraradicular dentin. J Endod. 2005;31(11):809-813.

8. Torabinejad M, Handysides R, Khademi AA, Bakland LK. Clinical implications of the smear layer in endodontics: a review. Oral Surg Oral Med Oral Pathol Oral Radiol Endod. 2002;94(6):658-666.

9. Card SJ, Sigurdsson A, Ørstavik D, Trope M. The effectiveness of increased apical enlargement in reducing intracanal bacteria. $J$ Endod. 2002;28(11):779-783.

10. Lewinstein I, Fuhrer N, Gelfand K, Cardash H, Pilo R. Retention, marginal leakage, and cement solubility of provisional crowns cemented with temporary cement containing stannous fluoride. Int J Prosthodont. 2003;16(2):189-193.

11. Kayaoglu G, Erten H, Alaçam T, Ørstavik D. Short-term antibacterial activity of root canal sealers towards Enterococcus faecalis. Int Endod Jl. 2005;38(7):483-488.

12. Holt KB, Bard AJ. Interaction of silver(I) ions with the respiratory chain of Escherichia coli: an electrochemical and scanning electrochemical microscopy study of the antimicrobial mechanism of micromolar $\mathrm{Ag}^{+}$. Biochemistry. 2005;44(39):13214-13223.

13. Kumar R, Münstedt $H$. Silver ion release from antimicrobial polyamide/ silver composites. Biomaterials. 2005;26(14):2081-2088.

14. Alt V, Bechert T, Steinrücke $P$, et al. An in vitro assessment of the antibacterial properties and cytotoxicity of nanoparticulate silver bone cement. Biomaterials. 2004;25(18):4383-4391.

15. Ohashi S, Saku S, Yamamoto K. Antibacterial activity of silver inorganic agent YDA filler. J Oral Rehabil. 2004;31(4):364-367.

16. Mo AC, Xu W, Xian SQ, Li YB, Bai S. Antibacterial activity of silverhydroxyapatite/titania nanocomposite coating on titanium against oral bacteria. Key Eng Mater. 2007;330:455-458.

17. Liao J, Mo AC, Wu HK, Zhang JC, Li YB, Lv GY. Antibacterial activity of silver-hydroxyapatite/titania nanoparticles on oral bacteria. Key Eng Mater. 2007;330:299-302.

18. Clark-Holke D, Drake D, Walton R, Rivera E, Guthmiller JM. Bacterial penetration through canals of endodontically treated teeth in the presence or absence of the smear layer. J Dent. 2003;31(4):275-281.

19. Keskin S, Usanmaz A. Hydroxyl-terminated poly(urethane acrylate) as a soft liner in dental applications: Synthesis and characterization. Journal of Applied Polymer Science. 2010;117(1):458-466.

20. Zuber M, Tabasum S, Jamil T, et al. Biocompatibility and microscopic evaluation of polyurethane-poly(methyl methacrylate)-titanium dioxide based composites for dental applications. J Appl Polym Sci. 2014;131(3): DOI 10.1002/app.39806.

21. Hsieh KH, Liao KH, Lai EH, Lee BS, Lee CY, Lin CP. A novel polyurethane-based root canal-obturation material and urethane acrylate-based root canal sealer-part I: synthesis and evaluation of mechanical and thermal properties. J Endod. 2008;34(3):303-305.

22. Sun B, Zuo Y, Li JD, et al. High conversion self-curing sealer based on a novel injectable polyurethane system for root canal filling. Mater Sci Eng C. 2013;33(6):3138-3145.

23. Li S, Vatanparast R, Lemmetyinen H. Cross-linking kinetics and swelling behaviour of aliphatic polyurethane. Polymer. 2000;41(15):5571-5576.

24. Weiss EI, Shalhav M, Fuss Z. Assessment of antibacterial activity of endodontic sealers by a direct contact test. Dent Traumatol. 1996;12(4): 179-184.

25. Liu J, Ma D, Li Z. FTIR studies on the compatibility of hard-soft segments for polyurethane-imide copolymers with different soft segments. Eur Polym J. 2002;38(4):661-665.

26. Heitman EP, Joyce AP, McPherson JC 3rd, Roberts S, Chuang A. An in vitro evaluation of the growth of human periodontal ligament fibroblasts after exposure to a methacrylate-based endodontic sealer. J Endod. 2008;34(2):186-189.

27. Lodiene G, Morisbak E, Bruzell E, Ørstavik D. Toxicity evaluation of root canal sealers in vitro. Int Endod J. 2008;41(1):72-77.

28. Oooka S, Miyazaki M, Takamizawa T, Tsubota K, Kurokawa H, Rikuta A. Influence of adhesive polymerization mode on dentin bond strength of direct core foundation systems. J Oral Sci. 2004;46(3):185-189. 
29. Wu MK, Fan B, Wesselink PR. Leakage along apical root fillings in curved root canals. Part I: effects of apical transportation on seal of root fillings. J Endod. 2000;26(4):210-216.

30. Lewinstein I, Matalon S, Slutzkey S, Weiss EI. Antibacterial properties of aged dental cements evaluated by direct-contact and agar diffusion tests. J Prosthet Dent. 2005;93(4):364-371.

31. Herrera M, Castillo A, Bravo M, Liébana J, Carrión P. Antibacterial activity of resin adhesives, glass ionomer and resin-modified glass ionomer cements and a compomer in contact with dentin caries samples. Oper Dent. 1999;25(4):265-269.

32. An J, Zhang H, Zhang J, Zhao Y, Yuan X. Preparation and antibacterial activity of electrospun chitosan/poly(ethylene oxide) membranes containing silver nanoparticles. Colloid Polym Sci. 2009;287(12): 1425-1434.

33. Xiu ZM, Ma J, Alvarez PJJ. Differential effect of common ligands and molecular oxygen on antimicrobial activity of silver nanoparticles versus silver ions. Environ Sci Tech. 2011;45(20):9003-9008.

34. Clement JL, Jarrett PS. Antibacterial silver. Met Based Drugs. 1994;1(5-6):467-482.
35. Feng QL, Wu J, Chen GQ, Cui FZ, Kim TN, Kim JO. A mechanistic study of the antibacterial effect of silver ions on Escherichia coli and Staphylococcus aureus. J Biomed Mater Res. 2000;52(4):662-668.

36. Liao C, Yu P, Zhao J, Wang L, Luo Y. Preparation and characterization of NaY/PVDF hybrid ultrafiltration membranes containing silver ions as antibacterial materials. Desalination. 2011;272(1):59-65.

37. Çobankara FK, Altinöz HC, Erganiş O, Kav K, Belli S. In vitro antibacterial activities of root-canal sealers by using two different methods. J Endod. 2004;30(1):57-60.

38. Ferracane JL. Elution of leachable components from composites. J Oral Rehab. 1994;21(4):441-452.

39. Goldberg M. In vitro and in vivo studies on the toxicity of dental resin components: a review. Clin Oral Investig. 2008;12(1):1-8.

40. Leonardo MR, Bezerra da Silva LA, Filho MT, Santana da Silva R. Release of formaldehyde by 4 endodontic sealers. Oral Surg Oral Med Oral Pathol Oral Radiol Endod. 1999;88(2):221-225.
International Journal of Nanomedicine

\section{Publish your work in this journal}

The International Journal of Nanomedicine is an international, peerreviewed journal focusing on the application of nanotechnology in diagnostics, therapeutics, and drug delivery systems throughout the biomedical field. This journal is indexed on PubMed Central, MedLine, CAS, SciSearch ${ }^{\circledR}$, Current Contents ${ } /$ Clinical Medicine,

\section{Dovepress}

Journal Citation Reports/Science Edition, EMBase, Scopus and the Elsevier Bibliographic databases. The manuscript management system is completely online and includes a very quick and fair peer-review system, which is all easy to use. Visit http://www.dovepress.com/ testimonials.php to read real quotes from published authors.

Submit your manuscript here: http://www.dovepress.com/international-journal-of-nanomedicine-journal 